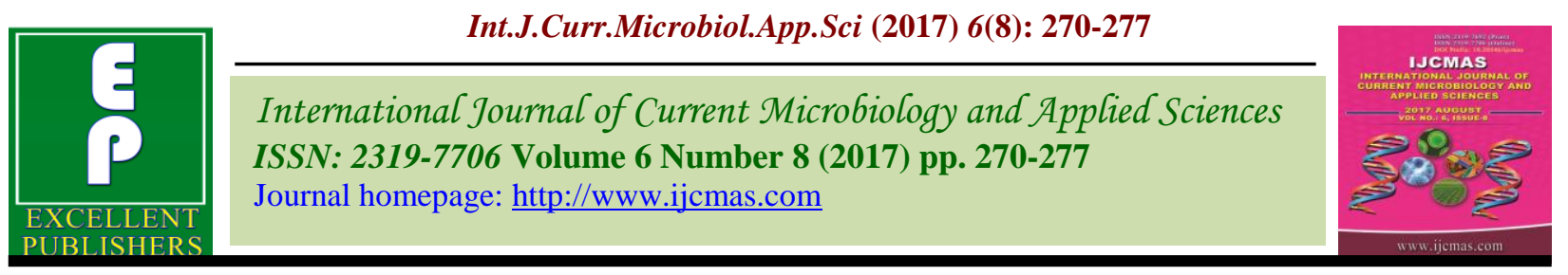

Original Research Article https://doi.org/10.20546/ijcmas.2017.608.036

\title{
Recovery of Resistant Thermophilic Campylobacters on Farm and Market Vegetables
}

\author{
A.B. Karikari ${ }^{1}$, K. Obiri-Danso ${ }^{2}$, E.H. Frimpong ${ }^{3}$ and K.A. Krogfelt ${ }^{4}$ \\ ${ }^{1}$ Department of Clinical Microbiology, University for Development Studies Tamale, Ghana \\ ${ }^{2}$ Department of Theoretical and Applied Biology, ${ }^{3}$ Department of Clinical Microbiology, Kwame \\ Nkrumah University of Science and Technology, Kumasi, Ghana, \\ ${ }^{4}$ Department of Microbiology and Infection Control, Statens Serum Institute Denmark \\ *Corresponding author
}

\section{A B S T R A C T}

This study focused on establishing the presence of Campylobacter at the farm and retail level and evaluated the antibiogram profile of isolated species. Campylobacter spp. were

Keywords

Antibiotic

resistance,

Vegetables, Farm, market, Ghana.

\section{Article Info}

Accepted:

04 June 2017

Available Online:

10 August 2017 isolated on mCCDA agar and confirmed by API Campy (biomereaux, France) and the susceptibility profile determined by Kirby-Bauer disk diffusion method. A total of 124 market vegetables comprising 59 lettuce and 65 cabbages and 117 farm vegetables made up of 94 lettuce and 23 cabbages were analysed. Prevalence of $41.9 \%$ (52/124) and 23.9\% $(28 / 117)$ were respectively documented in market and farm vegetables. Campylobacter jejuni was the dominant species keyed out from market vegetables $(61.5 \%)$ followed by $C$. coli $(23.0 \%)$, C. lari (11.5\%) and C. jejuni sub sp. doylei (3.8\%). Fifty percent (50\%) of farm vegetable isolates were $C$. jejuni, $25 \%$ constituted $C$. jejuni sub sp. doylei and $21.4 \%$, $3.6 \%$ were $C$. coli and $C$. lari respectively. All isolates (100\%) were multidrug resistant, with highest resistance observed against cephalexin, cefotaxime, ampicillin, erythromycin and chloramphenicol (86-100\%), 64-75\% against tetracyclines, 32-49\% to ciprofloxacin, nalidixic acid and norfloxacin and $57-67 \%$ to trimethoprim sulphamethoxazole. Against kanamycin and gentamicin resistance of $4-46 \%$ was obtained while no resistance $(0 \%)$ was observed against imipenem. The results provide baseline information on Campylobacter in vegetables and the possible risk it poses to consumers in the face of high level resistance in the species.

\section{Introduction}

Campylobacter are zoonotic pathogens that frequently cause diarrhoea in humans often surpassing salmonellosis and shigellosis with C. jejuni and C. coli species mostly implicated (EFSA, 2013; WHO, 2015). Consumption of undercooked meat is the main source of human infections and the most significant risk factor. Nevertheless, environmental routes such as faecally contaminated water serving as conduits for the dissemination of pathogens to foods of non-animal origin have been recognized (Kumar et al., 2001).

Campylobacter resilience to harsh environmental conditions have been proven by several studies contrary to earlier reports of its environmental fragility indicating nonsurvival on vegetables for a long period of time (Solomon and Hoover, 1999). 
Campylobacter presence in the environment, particularly in water as well as soil is well documented (Chai et al., 2007; Chai et al., 2009). The use of Campylobactercontaminated water to wash vegetables may result in banking the organism on the surface of the product. Also, leafy vegetables irrigated with untreated water or cultivated in Campylobacter contaminated soils are likely to carry the pathogen (Thomas et al., 1999).

The significance of vegetables as important source of campylobacteriosis is supported by the numerous outbreaks linked with raw vegetables, as salad vegetables are considered to be the second highest risk factor for Campylobacter infection after consumption and preparation of chicken (CDC, 2000; Evans et al., 2003; Abadias et al., 2008; Verhoeff-Bakkenes et al., 2010).In Ghana most water bodies from which most vegetable farmers depend on as irrigation sources, have been greatly polluted from human activities such as indiscriminate waste disposal. Some studies from Africa have determined the presence of other pathogenic microorganisms on raw vegetables at the farm and retail level (Amoah et al., 2005) but very limited information is available on the occurrence of Campylobacter on this product.

This study reports on the presence of Campylobacter spp. on vegetables at the farm (Pre-harvest) and market stage (Post- harvest) and the resistance profile of isolated species.

\section{Materials and Methods}

\section{Sampling}

Fresh vegetables (cabbage and lettuce) were randomly purchased from the Central market as well as six other satellite markets in the Kumasi metropolis. Eleven (11) major vegetable farms were also visited early mornings (before 9:00am) where lettuce and cabbages were obtained for study. At each farm visit, fresh vegetables (either cabbage or lettuce) were randomly picked from vegetable beds depending on the availability at the time of visit. All samples were returned on ice packs to the laboratory for analysis. Sampling took place from May 2013 to February 2014.

\section{Culture, identification and confirmation}

A 20-g sample of lettuce or cabbage was cut into pieces and placed into a sterile ziplock bag containing $180 \mathrm{ml}$ sterile $0.1 \%$ peptone water and pulsified for 30s using a Microgen Pulsifier (Bioproducts, UK). One $\mathrm{ml}(1 \mathrm{ml})$ aliquots were transferred into $5 \mathrm{ml}$ of bloodfree Campylobacter enrichment broth (Oxoid CM0963) supplemented with CCDA supplement (Oxoid SRO155E) in a bijou bottle and incubated at $37^{\circ} \mathrm{C}$ overnight. A loopful of the overnight culture was plated directly onto CCDA agar plates and incubated microaerophilically (CampyGen Oxoid CN0025A) at $42^{\circ} \mathrm{C}$ for $48 \mathrm{~h}$. Typical colonies were cultured on Nutrient agar from which Gram stain, catalase and oxidase test were performed. Small, curved, catalase and oxidase positive Gram negative rods were presumptively identified as Campylobacter spp. These isolates were further confirmed and characterized by API CAMPY system (bioMerieux, France).

\section{Antibiotic susceptibility test}

Antibiotic susceptibility tests were carried out by the Kirby-Bauer disk diffusion method on Mueller-Hinton agar (Liofilchem-Italy) supplemented with 5\% sheep blood following CLSI guidelines. Tested antibiotics and their corresponding concentrations were: Ampicillin (10 $\mu \mathrm{g} /$ disc $)$, chloramphenicol (30 $\mu \mathrm{g} / \mathrm{disc})$, ciprofloxacin $\quad(5 \mu \mathrm{g} / \mathrm{disc})$, kanamycin $\quad(30 \mu \mathrm{g} / \mathrm{disc}), \quad$ erythromycin $(15 \mu \mathrm{g} / \mathrm{disc})$, gentamicin $(10 \mu \mathrm{g} / \mathrm{disc})$, nalidixic acid $(30 \mu \mathrm{g} /$ disc $)$, tetracycline $(30 \mu \mathrm{g} / \mathrm{disc})$, 
cephalexin $\quad(30 \mu \mathrm{g} / \mathrm{disc}), \quad$ trimethoprim sulfamethoxazole $(25 \mu \mathrm{g} /$ disc $)$, norfloxacin $(10 \mu \mathrm{g} / \mathrm{disc})$, cefotaxime $(30 \mu \mathrm{g} / \mathrm{disc})$ and imipenem $(10 \mu \mathrm{g} / \mathrm{disc})$. Mueller-Hinton agar plates were inoculated with $0.5 \mathrm{Mcfarland}$ suspension and incubated under microaerophilic condition at $48^{\circ} \mathrm{C}$ for 24hours. The zones of inhibition were recorded and results interpreted according to EUCAST and CLSI breakpoints for Campylobacter. Quality control was attained by E. coli (ATCC25922) and S. aureus (ATCC25923) strains.

\section{Statistical analysis}

Percentages were used for the descriptive analysis. Associations were determined using the Chi-square test at a significance level of $<$ 0.05. Stata 14.0 software was used for statistical analysis.

\section{Results and Discussion}

Of the 124 market vegetable samples (59 lettuce and 65 cabbage) and the 117 farm vegetables (94 lettuce and 23 cabbage), 52 (27 cabbage, 25 lettuce) and 28 (7 cabbage, 21 lettuce) isolates were confirmed as Campylobacter with a prevalence rate of $41.9 \%(52 / 124)$ in market vegetables and $23.9 \%(28 / 117)$ in farm vegetables. There were statistically significant $(\mathrm{p}=0.003)$ differences in the isolation frequency of Campylobacter from market and farm vegetable samples (Table 1).

In the market vegetable samples, Campylobacter jejuni was most prevalent (61.5\%) followed by C. coli $(23.0 \%), C$. lari $(11.5 \%)$ and $C$. jejuni sub sp. doylei (3.8\%). Similarly, $50 \%$ of farm vegetable isolates were C. jejuni, $25 \%$ C. jejuni sub sp. doylei, $21.4 \%$ C. coli and $3.5 \%$ C. lari (Table 2). Market vegetable strains showed resistance of $98 \%, 96 \%, 90 \%, 75 \%$ and $67 \%$ respectively to Ampicillin, erythromycin, chloramphenicol, tetracycline and trimethoprim sulfamethoxazole. Against the cephalosporins; resistance was $100 \%$ each to cephalexin and cefotaxime. Resistance to the quinolones was $49 \%$ to ciprofloxacin, $44 \%$ to nalidixic acid, and $35 \%$ to norfloxacin. Against the aminoglycosides, resistance was $46 \%$ to gentamicin and $25 \%$ to kanamycin; as $0 \%$ resistance was observed against imipenem (Table 3).

Farm vegetable isolates showed resistance of $100 \%, 96 \%, 93 \%, 64 \%$ and $57 \%$ respectively to erythromycin, chloramphenicol, Ampicillin, tetracycline and trimethoprim sulfamethoxazole. Against the cephalosporins; resistance was $100 \%$ to cephalexin and $86 \%$ to cefotaxime. Resistance to the quinolones was $46 \%$ each against nalidixic acid and ciprofloxacin and $32 \%$ to norfloxacin. Against the aminoglycosides; resistance was $11 \%$ to kanamycin and $4 \%$ to gentamicin; as $0 \%$ resistance was to imipenem.

About sixty five percent (65.4\%) of Campylobacter jejuni, $23.1 \%$ of $C$. coli and $11.5 \%$ of $C$. lari strains from market vegetables were multidrug resistant. Among farm vegetable isolates $75.0 \%$ of $C$. jejuni, $21.4 \%$ of $C$. coli and $3.6 \%$ of $C$. lari strains were multidrug resistant. The difference in multidrug resistance between farm and market vegetable strains was not statistically significant $(\mathrm{p}=1.000)$ (Table 4$)$.

Globally, there is limited data on Campylobacter contamination in vegetables (Kumar et al., 2001; Chai et al., 2007). Our study found $41.8 \%$ Campylobacter contamination of market vegetables and $23.9 \%$ of farm vegetables. Market vegetable contamination with Campylobacter in our study is consistent with the work of Hussain et al., (2007) who reported $40.9 \%$ in 
vegetables from retailers in Pakistan and $52.6 \%$ in Malaysia by Khalid et al., (2014). Much lower levels; $3.1 \%, 3.57 \%$, and $7.5 \%$ have also been reported in Canada, India and Brazil, respectively (Park and Sanders, 1992; Kumar et al., 2001; Carvalho et al., 2013). Contamination levels of $18.8 \%$ and $35.2 \%$ have also been reported by Chai et al., (2009) and Khalid et al., (2014) in farm vegetables.

Campylobacteron vegetables at pre-harvest stage (farms) may come from faecally polluted irrigation water, use of poultry manure for soil enrichment and use of raw sewage sludge (Jones et al., 1990; Kumar et al., 2001; Chai et al., 2009; VerhoeffBakkenes et al., 2011). Moreover, most of the irrigation sources in this study region have been greatly polluted through indiscriminate waste disposal; it is therefore fair to partly attribute the source of Campylobacter contamination to these faecally polluted water sources.

Similarly, reasons for the contamination of vegetables at post-harvest stage (market) may be due to the display of vegetables on bare floors, or on old sacks laid on the floor, sprinkling of vegetables with poor quality water to keep them fresh, improper hygiene of the market women, packing and sorting and transportation in rickety public buses or taxis to the markets. These practices which are common among people involved in vegetable trade in the study region have also been confirmed by several authors as sources of contamination (Beuchat, 1996; Beuchat, 2002; Amoah et al., 2007; Chai et al., 2007).

Table.1 Prevalence of Campylobacter from farm and market vegetables

\begin{tabular}{lccc}
\hline $\begin{array}{l}\text { Vegetable } \\
\text { Source }\end{array}$ & $\begin{array}{c}\text { No. } \\
\text { Samples }\end{array}$ & $\begin{array}{c}\text { Nompylobacter } \\
\text { Identified N (\%) }\end{array}$ & $\begin{array}{c}\text { P-value } \\
\text { (Chi-square, df) }\end{array}$ \\
\hline Market & 124 & $52(41.9)$ & 0.003 \\
Farm & 117 & $28(23.9)$ & $(8.799,1)$ \\
Total & 241 & $80(33.2)$ & \\
\hline
\end{tabular}

Table.2 Species specific prevalence of Campylobacter from vegetable farms and markets in Kumasi

\begin{tabular}{lccccc}
\hline Vegetable source & $\begin{array}{c}\text { No. isolates } \\
(\mathrm{N})\end{array}$ & $\begin{array}{c}\text { C. jejuni } \\
(\%)\end{array}$ & $\begin{array}{c}\text { C. doylei } \\
(\%)\end{array}$ & $\begin{array}{c}\text { C. coli } \\
(\%)\end{array}$ & $\begin{array}{c}\text { C. lari } \\
(\%)\end{array}$ \\
\hline Market & 52 & $32(61.5)$ & $2(3.8)$ & $12(23.0)$ & $6(11.5)$ \\
Farm & 28 & $14(50.0)$ & $7(25.0)$ & $6(21.4)$ & $1(3.5)$ \\
& & & & & \\
\hline Total & 80 & 46 & 9 & & \\
\hline \multicolumn{2}{c}{ C. doylei= C. jejuni sub. sp. doylei } & & &
\end{tabular}


Table.3 Resistance and susceptibility patterns of Campylobacter from vegetable farms and market

\begin{tabular}{|c|c|c|c|}
\hline Antibiotic & Sensitive (\%) & Intermediate $(\%)$ & Resistant (\%) \\
\hline \multicolumn{4}{|c|}{ Farm $(\mathrm{N}=28)$} \\
\hline Nalidixic acid & 54 & NA & 46 \\
\hline Tetracycline & 22 & 14 & 64 \\
\hline Erythromycin & 0 & NA & 100 \\
\hline Ciprofloxacin & 25 & 29 & 46 \\
\hline Chloramphenicol & 4 & 0 & 96 \\
\hline Ampicillin & 4 & 3 & 93 \\
\hline Cefotaxime & 14 & 0 & 86 \\
\hline Kanamycin & 56 & 36 & 8 \\
\hline Gentamicin & 93 & 3 & 4 \\
\hline Norfloxacin & 57 & 11 & 32 \\
\hline SXT & 43 & 0 & 57 \\
\hline Cephalexin & 0 & NA & 100 \\
\hline Imipenem & 68 & 32 & 0 \\
\hline \multicolumn{4}{|c|}{ Market $(\mathrm{N}=52)$} \\
\hline Nalidixic acid & 56 & NA & 44 \\
\hline Tetracycline & 19 & 6 & 75 \\
\hline Erythromycin & 4 & NA & 96 \\
\hline Ciprofloxacin & 34 & 17 & 49 \\
\hline Chloramphenicol & 0 & 10 & 90 \\
\hline Ampicillin & 2 & 0 & 98 \\
\hline Cefotaxime & 0 & 0 & 100 \\
\hline Kanamycin & 58 & 17 & 25 \\
\hline Gentamicin & 46 & 8 & 46 \\
\hline Norfloxacin & 59 & 6 & 35 \\
\hline SXT & 33 & 0 & 67 \\
\hline Cephalexin & 0 & NA & 100 \\
\hline Imipenem & 75 & 25 & 0 \\
\hline
\end{tabular}

Table.4 Multidrug resistance in Campylobacter species from vegetables

\begin{tabular}{cccc}
\hline & & \multicolumn{2}{c}{ Multi-drug resistance } \\
\cline { 3 - 4 } Vegetable & & & \\
isolates & Total & Market & Farm \\
\hline C. coli & 18 & $12(23.1)$ & $6(21.4)$ \\
C. lari & 7 & $6(11.5)$ & $1(3.6)$ \\
C. jejuni & 55 & $34(65.4)$ & $21(75.0)$ \\
\hline Total & 80 & 52 & 28 \\
\hline
\end{tabular}

NB: C. jejuni sub sp. doylei was counted as part of $C$. jejuni isolates 
Campylobacter jejuni was the dominant species identified in this study which is consistent with works from other countries. In our market vegetables, $61.5 \%$ were $C$. jejuni and $23.0 \%$ C. coli and $50 \%$ and $21.4 \%$ were $C$. jejuni and $C$. coli in the farm vegetables. In Canada, Park and Sanders (1992) reported $88 \%$ of $C$. jejuni and $4 \%$ C. coli in vegetables purchased from outdoor markets and supermarkets while in Malaysia, Chai et al., (2007) reported $40.7 \%$ C. jejuni and $35.2 \%$ C. coli from supermarkets. The high isolation rate of $C$. jejuni as opposed to $C$. coli supports the theory that $C$. jejuni is more resilient to environmental stresses (Gonzalez and Hänninen, 2012; Bronowski et al., 2014); as Chai et al., (2009) also failed to isolate $C$. coli from soil and manure in Malaysia.

Antibiotic resistance profiles of the Campylobacter species were generally high with isolates showing 100\% multidrug resistance. Highest resistance was observed against cephalexin, cefotaxime, ampicillin, erythromycin and chloramphenicol with resistance ranging from $86-100 \%$ in both market and farm vegetables. Resistance rates of below fifty percent (32-49\%) were recorded for the quinolones (ciprofloxacin, nalidixic acid and norfloxacin), $64-75 \%$ for tetracyclines and $57-67 \%$ for trimethoprim sulphamethoxazole. However, 4-46\% was obtained against the aminoglycosides while no resistance $(0 \%)$ was observed against imipenem.

In Malaysia, isolates from vegetables has been reported to be $100 \%$ multidrug resistant (Chai et al., 2008).

The uncontrolled use of antimicrobial agents in agriculture and in hospitals cannot be totally excluded as a lead to the high rates of resistance recorded in this study. In Ghana, reports of increasing resistance to several pathogens have been reported in both human and animals (Donkor et al., 2008; Newman et al., 2011). The prevalence of Campylobacter spp. in vegetables is generally believed to be due to cross-contamination from sources such as humans, birds, livestock, and environmental water sources. In most developing countries, despite the ban of fluoroquinolones application in agriculture, the tetracyclines and fluoroquinolones are extensively applied in farming practices (Turkson, 2008; Newman et al., 2011). Besides, agricultural extension officers and veterinarians are not consulted before drug application often resulting in abuse.

In conclusion, campylobacter species have been established in vegetables from Kumasi at the pre- harvest (farms) and post- harvest stage (markets). Multidrug resistant strains of Campylobacter isolated poses direct risk to consumers since vegetables (cabbages and lettuce) are normally served raw at most food joints in Ghana. It is essential that vegetables are well decontaminated to ensure that they are free of pathogens such as Campylobacters prior to consumption. Much attention should be given to the increasing resistance of pathogens including Campylobacter to commonly used antibiotics in Ghana through comprehensive research and education to control the resistance menace.

\section{Acknowledgement}

We acknowledge Prof. Niels Frimodt-Møller and ADMER (www.admerproject.org) for funding this study.

\section{References}

Abadias, M., Usall J, Anguera M., Solsona C. and Viñas, I. 2008. Microbiological quality of fresh, minimally-processed fruit and vegetables, and sprouts from retail establishments. Int. J. Food Microbiol., 123: 121-129. 
Amoah, P., Drechsel, P. and Abaidoo, R.C. 2005. Irrigated urban vegetable production in Ghana: sources of pathogen contamination and health risk elimination. Irrigation and Drainage, 54: 49-61.

Amoah, P., Drechsel, P., Abaidoo, R.C. and Klutse, A. 2007. Effectiveness of common and improved sanitary washing methods in selected cities of West Africa for the reduction of coliform bacteria and helminth eggs on vegetables. Trop. Med. Int. Health, 12(2): 40-50.

Beuchat, L.R. 1996. Pathogenic microorganisms associated with fresh produce. J. Food Protection, 59: 204 216.

Beuchat, L.R. 2002. Ecological factors influencing survival and growth of human pathogens on raw fruits and vegetables. Microbes Infections, 4: 413423.

Bronowski, C., James, C.E. and Winstanley, C. 2014. Role of environmental survival in transmission of Campylobacter jejuni. FEMS Microbiol. Lett., 356: 819.

Carvalho, A.F., Martins da Silva, D., Azevedo, S.S., Piatti, R.M., Genovez, M.E. and Scarcelli, E. 2013. Detection of CDT toxin genes in Campylobacter spp. strains isolated from broiler carcasses and vegetables in São Paulo, Brazil. Brazillian J. Microbiol., 44: 3.

CDC. 2000. Centers for Disease Control and Prevention, U. S. Foodborne Disease Outbreak Line Listing, 1990-1999.

Chai, L.C., Robin, T., Ragavan, U.M., Gunsalam, J.W., Bakar, F.A., Ghazali F.M., Radu, S. and Kumar, M.P. 2007. Thermophilic Campylobacter spp. in salad vegetables in Malaysia. Int. J. Food Microbiol., 117: 106-111.

Chai, L.C., Fatimah, A.B., Ghazali, F.M., Lee, H.Y., Tunung, R., Shamsinar,
A.T., Laila, R.A.S., Thaihirahtul, A.Z., Malakar, P.M., Nakaguchi. Y., Nishibuchi, M. and Son, R. 2008. Biosafety of Campylobacter jejuni from raw vegetables consumed as Ulam with reference to their resistance to antibiotics. Int. Food Res. J., 15(2): 125-134.

Chai, L.C., Ghazali, F.M., Bakar, F. A., Lee, H.Y., Suhaimi, L.R.A., Talib, S.A., Nakaguchi, Y., Nishibuchi, M. and Radu, S. 2009. Occurrence of thermophilic Campylobacter spp. contamination on vegetable farms in Malaysia. J. Microbiol. Biotechnol., 19: 1415-1420.

Donkor, E.S., Nortey, T., Opintan, J.A., Dayie, N. and Akyeh, M.L. 2008. Antimicrobial susceptibility of Salmonella typhi and Staphylococcus aureus isolates and the effect of some media on susceptibility testing results. The Internet J. Microbiol., Vol. 4.

EFSA. 2013. The European Union summary report on trends and sources of zoonoses, zoonotic agents and foodborne outbreaks in 2011. EFSA J., 11(4): 3129.

Evans, M.R., Ribeiro, C.D. and Salmon, R.L. 2003. Hazards of healthy living: bottled water and salad vegetables as risk factors for Campylobacter infection. Emerging Infect. Dis., 9: 1219-1225.

Gonzalez, M. and Hänninen, M.L. 2012. Effect of temperature and antimicrobial resistance on survival of Campylobacter jejuni in well water: application of the Weibull model. J. Appl. Microbiol., 113(2): 284-293.

Hussain, I., Shahid Mahmood, M., Akhtar, M. and Khan, A. 2007. Prevalence of Campylobacter species in meat, milk and other food commodities in Pakistan. Food Microbiol., 24: 219-222.

Jones, K., Betaieb, M. and Telford, D.R. 1990. Seasonal variation of 
thermophilic Campylobacters in sewage sludge. J. Appl. Bacteriol., 69: 185-189.

Khalid, M.I., Tang, J.Y.H., Baharuddin, N.H., Rahman, N.S., Rahimi, N.F. and Radu, S. 2015. Prevalence, Antibiogram, and cdt Genes of Toxigenic Campylobacter jejuni in Salad Style Vegetables (Ulam) at Farms and Retail Outlets in Terengganu. J. Food Protection, 78: 6571.

Kumar, A., Argawal, R.K., Bhilekaonkar, K.N., Shome, B.R., Bachhil, B.N. 2001. Occurrence of Campylobacter jejuni in vegetables. Int. J. Food Microbiol., 67: 153-155.

Newman, M.J., Frimpong, E., Donkor, E.S., Opintan, J.A. and Asamoah-Adu, A. 2011. Resistance to antimicrobial drugs in Ghana. Infection and Drug Resistance, 4: 215-220.

Park, C.E. and Sanders, G.W. 1992. Occurrence of thermotolerant
Campylobacters in fresh vegetables sold at farmers outdoor markets and supermarkets. Canadian J. Food Microbiol., 38: 313-316.

Solomon, E.B. and Hoover, D.G. 1999. Campylobacter jejuni: a bacterial paradox. J. Food Safety, 19: 121-136.

Thomas, C., Gibson, H., Hill, D.J. and Mabey, M. 1999.Campylobacter epidemiology: an aquatic perspective. $J$. Appl. Microbiol., 85: 158S-177S.

Turkson, P.K. 2008. Use of drugs and antibiotics in Ghana. Ghana J. Agri. Sci., 41: 23-33.

Verhoeff-Bakkenes, L., Jansen, H.A.P.M., Beumer R.R., Zwietering, M.H. and van Leusden, F.M. 2011. Consumption of raw vegetables and fruits: A risk factor for Campylobacter infections. Int. J. Food Microbiol., 144(3): 406-412.

WHO. 2015. Water Sanitation and Health (WHS): Water-related diseases.

\section{How to cite this article:}

Karikari, A.B., K. Obiri-Danso, E.H. Frimpong and Krogfelt, K.A. 2017. Recovery of Resistant Thermophilic Campylobacters on Farm and Market Vegetables. Int.J.Curr.Microbiol.App.Sci. 6(8): 270-277. doi: https://doi.org/10.20546/ijcmas.2017.608.036 